\title{
ASO Author Reflections: Opportunities for Improving HIPEC Outcomes
}

\author{
June S. Peng, $\mathrm{MD}^{1}$ (D) , and Valerie A. Francescutti, MD, $\mathrm{MSc}^{2}$ \\ ${ }^{1}$ Division of Surgical Oncology, Department of Surgery, Penn State College of Medicine, Hershey, PA; ${ }^{2}$ Department of \\ Surgery, McMaster University, Hamilton, ON, Canada
}

Historically, the intraoperative management of surgical patients has favored liberal fluid administration, with the rationale of counteracting volume depletion caused by prolonged fasting and bowel preparation, the vasodilatory effect of anesthetics, positive pressure ventilation, sympathetic blockade with neuraxial anesthesia, sequestration of fluid, bleeding, and insensible losses. The added component of hyperthermia in patients undergoing cytoreductive surgery (CRS) and hyperthermic intraperitoneal chemotherapy (HIPEC) typically has favored an even more liberal fluid administration strategy due to perception of increased insensible losses and need for renal protection.

More recently, the paradigm for fluid management in CRS/HIPEC has slowly shifted toward restrictive strategies and goal-directed fluid therapy (GDFT). The Italian randomized trial demonstrated the superiority of GDFT over standard management, with lower rates of major abdominal complications and shorter hospital stays. ${ }^{1}$ Numerous retrospective, single- and multi-institution studies have also reported that lower intraoperative fluid volume is associated with fewer complications and lower readmission rates, as discussed in the accompanying article. ${ }^{2}$

(C) Society of Surgical Oncology 2021

First Received: 8 September 2021

Accepted: 8 September 2021;

Published Online: 28 September 2021

J. S. Peng, MD

e-mail: jpeng1@ pennstatehealth.psu.edu
Although the current morbidity rate of HIPEC is substantial, many components of intra- and perioperative management can be targeted to minimize the risks of these operations. Preoperative optimization for patients with metastatic cancer is often difficult, and the results presented in this study and by other groups suggest that a paradigm shift in intraoperative fluid management would be potentially beneficial.

DISCLOSURE Valerie A. Francescutti is a consultant for Novartis. There are no other conflicts of interest.

\section{REFERENCES}

1. Colantonio L, Claroni C, Fabrizi L, et al. A randomized trial of goal-directed vs standard fluid therapy in cytoreductive surgery with hyperthermic intraperitoneal chemotherapy. J Gastrointest Surg. 2015;19:722-9.

2. Peng JS, LaPiano J, Wang K, et al. Restrictive intraoperative fluid rate is associated with improved outcomes in cytoreductive surgery and hyperthermic intraperitoneal chemotherapy. Ann Surg Oncol. 2021. https://doi.org/10.1245/s10434-021-10556-3.

Publisher's Note Springer Nature remains neutral with regard to jurisdictional claims in published maps and institutional affiliations. 